\title{
Evaluation of Serum Levels of Lactate Dehydrogenase Isoenzymes in COVID- 19 Patients
}

\author{
*Sara Ali Mutashar \\ **Dr.Wasan Taha Saadoon \\ ***Prof.Dr.Abdul Hameed A M Al Qaseer \\ */Al-Nahrain University /College of Medicine / Department of Chemistry and Biochemistry \\ **/ Al-Nahrain University /College of Medicine / Department of Chemistry and Biochemistry \\ ***/ Al-Mustansyria University /College of Medicine / Department of Medicine \\ E-mail-mustafasaleamuob@gmail.com \\ Mobile- 009647725503941
}

\begin{abstract}
Background: This study aimed to determine the serum levels of lactate dehydrogenase isoenzymes (LDH1, LDH2, LDH3, LDH4, and LDH5) and their contribution to the total lactate dehydrogenase enzyme elevation observed in COVID-19 patients.

Design of study: This study was conducted in collaboration between Al-Nahrain University/College of Medicine/Chemistry and Biochemistry Department and AlYarmouk Teaching Hospital, Baghdad, Iraq. The study included 90 patients with confirmed COVID-19 infection: 45 with severe symptoms, and 45 with mild symptoms during the period from February 2021 to June 2021. The different LDH isoenzymes (LDH1, LDH2, LDH3, LDH4, and LDH5) were determined by enzyme-linked immunosorbent assay (ELISA) kits.

Results: This study showed high correlation between total lactate dehydrogenase (LDH) enzyme and disease progression and severity in patients with COVID-19. The study also showed significantly higher levels of the lactate dehydrogenase isoenzymes (LDH1, LDH3, and LDH4) in patients with severe symptoms.

Conclusion: This study suggests that elevation of serum lactate dehydrogenase (LDH) in patients with COVID-19 may be associated with the release of more than one of LDH isoenzymes into the bloodstream, therefore the use of total LDH as a specific biomarker for lung affectation in patients with COVID-19 is not specific, but the assay of all LDH isoenzymes could give a better understanding of the tissues most affected by the virus.
\end{abstract}

Keywords: COVID-19, Total lactate dehydrogenase enzyme, Lactate dehydrogenase isoenzymes 


\section{Introduction}

As of August 7, 2020, over nineteen million people have been confirmed infected by severe acute respiratory syndrome coronavirus 2 (SARS-CoV-2) globally and the pandemic has caused over seven hundred thousand deaths worldwide so far according to Johns Hopkins University Coronavirus Resource Center [1]. To effectively prioritize resources for the patients at high risk of mortality, identification of clinical and laboratory predictors of progression towards fatal forms is urgently needed. Lactate dehydrogenase (LDH) is a cytoplasmic enzyme which is widely expressed in tissues. The enzyme converts pyruvate, which is the final product of glycolysis, to lactate when oxygen is in short supply [2]. LDH comprises two separately enclosed subunits, resulting in five isozymes. Each isozyme is expressed in a specific organ: LDH 1 in cardiomyocytes, LDH 3 in lung tissue and LDH 5 in hepatocytes [3]. Increased LDH was observed in different conditions such as tissue injury, necrosis, hypoxia, hemolysis or malignancies [4, 5]. Additionally, Tao et al. found that LDH was associated with death in patients with community acquired pneumonia (CAP) caused by viruses [6]. Furthermore, LDH has been proved to be a prognostic factor with high accuracy in diseases involving multiple organ injuries such as acute heart failure (AHF) and severe acute pancreatitis (AP) [7, 8]. Coronavirus disease 2019 (COVID-19) is a disease that could cause multiple organ injuries including heart [9], liver and kidney injuries [13-16]. Similarly, a growing number of studies demonstrated that elevated LDH value was associated with significantly increased mortality in patients with COVID-19 [12]. But in most studies, patients with various levels of COVID-19 severity were pooled and analyzed, this may prevent accurate evaluation of the relationship between LDH and disease progression and in-hospital death because the majority of deaths were from severe and mild patients.

To our knowledge, not many studies have determined the contribution of the LDH isoenzymes to the total LDH elevation usually observed in COVID-19 patients. Therefore, this study aimed to investigate the association of LDH with the inhospital mortality in severe and mild patients with COVID-19 and estimate the predictive accuracy of total $\mathrm{LDH}$ and $\mathrm{LDH}$ isoenzymes.

\section{Patients, Materials and Methods: Patients: \\ Patients and study design:}


This is a cross sectional study that was conducted in Department of Chemistry and Biochemistry at the College of Medicine/ Al-Nahrain University and Al- Yarmouk Hospital City).

Ninety patients with confirmed COVID-19 infection: 45 with severe symptoms and 45 with mild symptoms participated in this study during the period from February 2021 to June 2021. All participants are > 18 years of age.

Patients with severe symptoms are patients who meet any of the following criteria as determined by the Iraqi Ministry of Health guidelines:

- Respiratory distress (RR > than $30 / \mathrm{m}$ in adults)

- Blood oxygen saturation lees than $93 \%$ on ambient air.

- Lung infiltrates $>50 \%$ of the lung field within 24 hours.

- Blood oxygen saturation leses than $93 \%$ on ambient air.

- Lung infiltrates $>50 \%$ of the lung field within 24 hours.

Exclusion criteria: patients with congestive heart failure, liver diseases, renal failure, diabetes mellitus, Any lung problems, and patients that were taking oral anticoagulants $>6$ month.

\section{Blood sample collection and storage:}

About $5 \mathrm{ml}$ of venous blood samples were obtained from all participants. The blood was left to clot for 15 minutes at room temperature. After coagulation, serum was separated by centrifugation at $3000 \mathrm{rpm}$ for 10 minutes.

Measurement of serum total LDH was performed using Cobas C311 analyzer.

Serum Human LDH-1 kit, Serum Human LDH-2 kit, Serum Human LDH-3 kit, Serum Human LDH-4 kit and Serum Human LDH-5 kit were all purchased from B.T.L Company, China.

Other tests performed include C-reactive protein (CRP), Ferritin, and D-dimer tests.

Statistical analyses were performed by using SPSS software version 25.0 (SPSS, Chicago). Mann-Whitney $U$ test was used to compare between severe and mild infected patient's total LDH levels, as well as the levels of the different LDH isoenzymes. The correlation between total $\mathrm{LDH}$ and its isoenzymes with quantitative variables in mild and severe cases was explored using Spearman's correlation test. A p- value less than 0.05 were considered to indicate a statistically significant difference.

\section{Results}

The mean age of the patients with severe symptoms was $57.51 \pm 10.8$ years which was higher than that of mild disease $(41.71 \pm 14.7$ years $)$ with highly significant difference, as shown in Table 1. 
Table 1: Demographic characteristics of the study population

\begin{tabular}{|l|l|l|l||}
\hline Variables & $\begin{array}{l}\text { Mild cases } \\
(\mathrm{n}=45)\end{array}$ & $\begin{array}{l}\text { Severe cases } \\
(\mathrm{n}=45)\end{array}$ & p- value* \\
\hline $\begin{array}{l}\text { Age, years } \\
\text { Mean } \pm \text { SD } \\
\text { Range }\end{array}$ & $\begin{array}{l}41.71 \pm 14.7 \\
22-74\end{array}$ & $\begin{array}{l}57.51 \pm 10.8 \\
35-80\end{array}$ & $<0.001$ \\
\hline $\begin{array}{l}\text { Gender } \\
\text { Male } \\
\text { Female }\end{array}$ & $25(55.56 \%)$ & $31(68.89 \%)$ & 0.277 \\
\hline
\end{tabular}

*P-value: 0.05 represents significant difference $>0.001$ highly significant difference

Serum total LDH was significantly higher in patients with severe symptoms than patients with mild symptoms $(\mathrm{p}<0.001)$

With the exception of LDH2 and LDH5, the LDH isoenzymes (LDH1, LDH3 and LDH4) were higher in severe than mild cases as shown in Table 2. All parameters were presented as mean \pm standard deviation with p-value: 0.05 represents significant difference, and $>0.001$ highly significant differences.

Table 2: Serum levels of total LDH and LDH isoenzymes

\begin{tabular}{|l||c|l|l||c|}
\hline Variables & $\begin{array}{l}\text { Normal } \\
\text { Range }\end{array}$ & $\begin{array}{l}\text { Mild cases } \\
(\mathrm{n}=45)\end{array}$ & $\begin{array}{l}\text { Severe cases } \\
(\mathrm{n}=45)\end{array}$ & p- value * \\
\hline $\begin{array}{l}\text { Total LDH, U/L } \\
\text { Mean } \pm \text { SD }\end{array}$ & Up to $250 \mathrm{U} / \mathrm{L}$ & $267.53 \pm 152.68$ & $444.36 \pm 200.53$ & $<\mathbf{0 . 0 0 1}$ \\
\hline $\begin{array}{l}\text { LDH1, ng/ml } \\
\text { Mean } \pm \text { SD }\end{array}$ & $3.3-6.5 \mathrm{ng} / \mathrm{ml}$ & $5.65 \pm 2.13$ & $9.0 \pm 2.53$ & $<\mathbf{0 . 0 0 1}$ \\
\hline $\begin{array}{l}\text { LDH2, ng/ml } \\
\text { Mean } \pm \text { SD }\end{array}$ & $3-7 \mathrm{ng} / \mathrm{ml}$ & $5.68 \pm 1.46$ & $4.92 \pm 1.12$ & $\mathbf{0 . 0 0 9}$ \\
\hline $\begin{array}{l}\text { LDH3, ng/ml } \\
\text { Mean } \pm \text { SD }\end{array}$ & $6-14 \mathrm{ng} / \mathrm{ml}$ & $11.51 \pm 8.2$ & $17.0 \pm 5.53$ & $\mathbf{0 . 0 0 4}$ \\
\hline $\begin{array}{l}\text { LDH4, ng/ml } \\
\text { Mean } \pm \text { SD }\end{array}$ & $3.1-12 \mathrm{ng} / \mathrm{ml}$ & $4.91 \pm 1.48$ & $7.71 \pm 4.32$ & $<\mathbf{0 . 0 0 1}$ \\
\hline $\begin{array}{l}\text { LDH5, ng/ml } \\
\text { Mean } \pm \text { SD }\end{array}$ & $0.9-2.8 \mathrm{ng} / \mathrm{ml}$ & $1.59 \pm 0.4$ & $0.68 \pm 2.34$ & $<\mathbf{0 . 0 0 1}$ \\
\hline
\end{tabular}

*P-value: 0.05 represents significant difference $>0.001$ highly significant difference 
D-dimer, ferritin and CRP were all significantly higher in patients with severe symptoms when compared to patients with mild symptoms, as given in Table 3.

Table 3: Serum levels of D-dimer,ferritin and CRP in both study groups

\begin{tabular}{|c|c|c|c|}
\hline Variables & \begin{tabular}{|l}
$\begin{array}{l}\text { Mild cases } \\
(\mathrm{n}=45)\end{array}$ \\
\end{tabular} & \begin{tabular}{|l} 
Severe cases \\
$(\mathrm{n}=45)$
\end{tabular} & p- value* \\
\hline $\begin{array}{l}\text { D-dimer, } \mathbf{m g} / \mathbf{L} \\
\text { Mean } \pm S D\end{array}$ & $0.34 \pm 0.26$ & $1.63 \pm 1.22$ & $<0.001$ \\
\hline $\begin{array}{l}\text { Ferritin, ng/ml } \\
\text { Mean } \pm \text { SD }\end{array}$ & $250.8 \pm 219.2$ & $559.9 \pm 273.9$ & $<0.001$ \\
\hline $\begin{array}{l}\text { CRP, mg/L } \\
\text { Mean } \pm \text { SD }\end{array}$ & $28.5 \pm 26.5$ & $54.7 \pm 26.8$ & $<0.001$ \\
\hline
\end{tabular}

*P-value: 0.05 represents significant difference $>0.001$ highly significant difference

Spearman correlation was used to explore the possible correlations between markers and other continuous variables. This study did not show any significant correlation between LDH isoenzymes and the other tests for patients with severe COVID-19 infection as shown in Table 4.

Table 4: Spearman correlation between LDH and its Isoenzymes and other parameters in patients with severe infection

\begin{tabular}{|l|l|l|l|l|l|l|l|l||}
\hline \multirow{2}{*}{ Variables } & \multicolumn{2}{l}{ age } & \multicolumn{2}{l|}{ D-dimer } & \multicolumn{2}{l||}{ CRP } & \multicolumn{2}{l|}{ Ferritin } \\
\cline { 2 - 9 } & $\mathrm{r}$ & $\begin{array}{l}\mathrm{p} \text { - } \\
\text { value }\end{array}$ & $\mathrm{r}$ & $\begin{array}{l}\mathrm{p}- \\
\text { value }\end{array}$ & $\mathrm{r}$ & $\begin{array}{l}\text { p- } \\
\text { value }\end{array}$ & $\mathrm{r}$ & p-value \\
\hline $\begin{array}{l}\text { Total } \\
\text { LDH }\end{array}$ & 0.007 & 0.964 & 0.209 & 0.168 & 0.135 & 0.378 & 0.171 & 0.261 \\
\hline LDH1 & 0.182 & 0.232 & $\mathbf{0 . 2 9 2}$ & $\mathbf{0 . 0 5}$ & -0.250 & 0.097 & 0.001 & 0.996 \\
\hline LDH2 & -0.008 & 0.960 & -0.084 & 0.584 & 0.190 & 0.212 & -0.113 & 0.459 \\
\hline LDH3 & -0.211 & 0.169 & 0.045 & 0.771 & 0.079 & 0.612 & -0.131 & 0.396 \\
\hline LDH4 & $\mathbf{- 0 . 3 4 1}$ & $\mathbf{0 . 0 2 2}$ & -0.134 & 0.382 & -0.115 & 0.452 & -0.151 & 0.322 \\
\hline LDH5 & 0.033 & 0.828 & -0.265 & 0.090 & 0.046 & 0.764 & -0.074 & 0.592 \\
\hline
\end{tabular}




\section{Discussion}

Our results suggests that the elevation of serum LDH levels in COVID-19 may be due to the release of more than one of the $\mathrm{LDH}$ isoenzymes into the bloodstream, in which it was found that (LDH1, LDH3, and LDH4) were significantly higher in patients with severe symptoms.

A study by P. Serrano-Lorenzo et., al., 2021, suggested that elevation of plasma LDH activity in patients with COVID-19 is not associated to a specific release of LDH-3 into the bloodstream, and they do not support the use of LDH as a specific biomarker for lung affectation in patients with COVID-19[12].

Juan MO. Et. Al., 2020, found that the patients with mild COVID-19 who are apt to develop severe diseases may be related to combined hypertension, decreased LYM, and longer PT, and increased CK level. For the mild patients with these clinical features, early intervention may effectively prevent the progression to severe diseases [13]

Another study by Y. Zhu et. al., 2020, showed that there were different degrees of damage to the liver, kidneys, blood coagulation, and heart function in the nonsurvival group. In addition, PLT, AST, BUN, CR, D-Dimer, PT, FIB, F VIII:C, $\mathrm{CK}-\mathrm{MB}, \mathrm{CK}$, and $\mathrm{LDH}$ had value in evaluating disease prognosis [14].

Therefore, the results obtained in this study agree with many other studies, in that COVID-19 infection causes direct damage to various organs and not only the lungs $[14,15,16,17]$.

\section{Conclusion}

The elevation in the levels of the LDH isoenzymes, could help to identify the main source of LDH release since they are relatively tissue-specific and thus may help in the early detection of damage in a certain tissue or even multiple organ damage. Therefore, adding the early analysis of LDH isoenzymes with other blood indicators might improve the survival rate of severely ill COVID-19 patients.

\section{Conflict of interest:}

The authors declare that there is no conflict of interests.

\section{References}

1. [Internet] https://coronavirus.jhu.edu/.

2. Feron O. Pyruvate into lactate and back: from the Warburg effect to symbiotic energy fuel exchange in cancer cells. Radiotherapy and oncology : journal of 
the European Society for Therapeutic Radiology and Oncology. 2009;92(3):329-33.

3. Glick JH, Jr. Serum lactate dehydrogenase isoenzyme and total lactate dehydrogenase values in health and disease, and clinical evaluation of these tests by means of discriminant analysis. American journal of clinical pathology. 1969;52(3):320-8.

4. Karlsson M, Wiberg-Itzel E, Chakkarapani E, Blennow M, Winbladh B, Thoresen M. Lactate dehydrogenase predicts hypoxic ischaemic encephalopathy in newborn infants: a preliminary study. Acta paediatrica (Oslo, Norway : 1992). 2010;99(8):1139-44.

5. Kato GJ, McGowan V, Machado RF, Little JA, Taylor Jt, Morris CR, et al. Lactate dehydrogenase as a biomarker of hemolysis-associated nitric oxide resistance, priapism, leg ulceration, pulmonary hypertension, and death in patients with sickle cell disease. Blood. 2006;107(6):2279-85.

6. Tao RJ, Luo XL, Xu W, Mao B, Dai RX, Li CW, et al. Viral infection in community acquired pneumonia patients with fever: a prospective observational study. Journal of thoracic disease. 2018;10(7):4387-95.

7. Yamaguchi S, Abe M, Arakaki T, Arasaki O, Shimabukuro M. Prognostic Value of Lactate Dehydrogenase for Mid-Term Mortality in Acute Decompensated Heart Failure: A Comparison to Established Biomarkers and Brain Natriuretic Peptide. Heart, lung \& circulation. 2019; [Epub ahead of print].

8. Cui J, Xiong J, Zhang Y, Peng T, Huang M, Lin Y, et al. Serum lactate dehydrogenase is predictive of persistent organ failure in acute pancreatitis. Journal of critical care. 2017;41:161-5.

9. Chen N, Zhou M, Dong X, Qu J, Gong F, Han Y, et al. Epidemiological and clinical characteristics of 99 cases of 2019 novel coronavirus pneumonia in Wuhan, China: a descriptive study. Lancet (London, England). 2020; 395(10223): 507-13.

10. Henry, B.M., Aggarwal, G., Wong, J., Benoit, S., Vikse, J., Plebani, M., Lippi, G., 2020. Lactate dehydrogenase levels predict coronavirus disease 2019 (COVID19) severity and mortality: A pooled analysis. Am. J. Emerg. Med. 38: 1722-1726. https://doi.org/10.1016/j.ajem.2020.05.073 
11. Davies, N.G., Klepac, P., Liu, Y., Prem, K., Jit, M., Eggo, R.M., 2020. Agedependent effects in the transmission and control of COVID-19 epidemics. Nat. Med. 26:1205-12.

12. Pablo Serrano-Lorenzo, Olga N. Coya, Ana López-Jimenez, Alberto Blázquez, Aitor Delmiro, Alejandro Lucia, Joaquín Arenas, Miguel A. Martín, Alejandro Santos-Lozano, Cecilia Cueto-Felgueroso, Alba Fernández-del Pozo, Montserrat de Miguel-Reyes. Plasma LDH: A specific biomarker for lung affectation in COVID-19. Practical Laboratory Medicine 25 (2021) e00226: 1-6. https://doi.org/10.1016/j.plabm.2021.e00226

13. MO Juan, LIU Jiyang, WU Songbai, LÜ Ailian, XIAO Le, CHEN Dong, ZHOU Yun, LIANG Lu, LIU Xiaofang, ZHAO Jinjin. Predictive role of clinical features in patients with coronavirus disease 2019 for severe disease[J]. Journal of Central South University. Medical Science, 2020, 45(5): 536-541. DOI: 10.11817/j.issn.1672-7347.2020.200384

14. Yingjie Zhu, Ziqiang Du, Yanfang Zhu, Wenfeng Li, Hongjun Miao, and Zhuo Li. Evaluation of organ function in patients with severe COVID-19 infections. Med Clin (Barc). 2020;155(5):191-196.

https://doi.org/10.1016/j.medcli.2020.05.012

15. Jiangyang L, Jingmin Z, Ning L, Bencheng Z, Ling L, Yi Y, et al. Electron microscopic observation of multiple organ damage caused by SARS related coronavirus infection. Infect Inflamm Repair. 2003:145-8.

16. Mehta P, McAuley Daniel F, Brown M, Sanchez S, Tattersall Rachel S, Manson Jessica J, et al. COVID-19: consider cytokine storm syndromes and immunosuppression. Lancet. 2020;395:1033-4, http://dx.doi.org/10.1016/S01406736(20)30628-0.

17. Xu Z, Shi L, Yijin W, Jiyuan Z, Huang L, Zhang C, et al. Pathological findings of COVID-19 associated with acute respiratory distress syndrome. Lancet Respir Med. 2020;8:420-2, http://dx.doi.org/10.1016/S2213-2600(20)30076-X 